\title{
Gestão da Qualidade - Os principais marcos e co- mo influenciaram as empresas
}

\author{
Title: Quality Management - The main milestones and their in influencing business
}

\author{
Renata Karine Viana da Silva \\ Escola Politécnica de Pernambuco \\ Universidade de Pernambuco \\ 50.720-001 - Recife, Brasil \\ r.kvianas@gmail.com
}

\author{
Ana de Fátima Braga Barbosa \\ Escola Politécnica de Pernambuco \\ Universidade de Pernambuco \\ 50.720-001 - Recife, Brasil \\ afbc.direito@yahoo.com.br
}

\begin{abstract}
Resumo Empresas em todo o globo tem passado por intensas mudanças que abrangem aspectos internos e externos em todas ás áreas de atuação. As observações às variáveis do micro e do macro ambiente são cruciais para as empresas. Analisar aspectos tais como relações político sociais, recursos e meio ambiente, todas as partes interessadas, clientes internos e externos cadeias de suprimentos fazem parte de todo este processo. Este é um processo em escala mundial onde os modelos de gerenciamentos buscam atingir estágios de desenvolvimento empresarial que atendam às exigências de um mundo cada vez mais globalizado e exigente. O processo de melhorias em inovação de processos e tecnológica, gerenciamento de custos, gerenciamento dos fluxos de materiais e muitos outros fatores relacionados ao ambiente interno e externo das organizações que influenciam diretamente para a competividade no mercado que atuam e prepara para mercados futuros. Este artigo abordará a adaptabilidade das organizações com relação a aspectos internos e externos para uma melhor utilização da Gestão da Qualidade e aumento da produtividade, bem como seu aprimoramento da própria competitividade dentro de uma ótica que permita a empresa sobreviver e vencer aos desafios proposto.
\end{abstract}

Palavras-Chave: Gestão da Qualidade, Produtividade, Competividade, Gerenciamento, Adaptabilidade, Processos

\begin{abstract}
Companies across the globe has experienced intense changes that cover internal and external aspects in all areas. The observations to micro and macro environment variables are crucial for businesses. Analyze aspects such as social political relations, resources and environment, all stakeholders, internal customers and external supply chains are part of this whole process. This is a process worldwide which models geren nancing seek to achieve business development stages that meet the demands of an increasingly globalized and demanding world. The process improvements in processes and technological innovation, cost management, management of material flows and many other factors related to internal and external environment of organizations that influence directly the competitiveness in the market that act and prepare for future markets. This article discusses-ha adaptability of organizations with respect to internal and external aspects to better use of quality management and increased productivity, as well as its own improvement of competitiveness within a perspective that allows the company to survive and win the proposed challenges.
\end{abstract}

Keywords: Quality Management, Productivity, Competitiveness, Management, Adaptability, Process 


\section{Introdução}

O presente estudo aborda como a Gestão de Qualidade influenciou as principais multinacionais e apontou os seus marcos históricos no processo de adequação nestas empresas. Nesta linha de pensamento, [1] entende-se que um produto ou serviço de qualidade é aquele que atende perfeitamente, de forma confiável, de forma acessível, de forma segura e no tempo certo às necessidades do cliente.

Para determinados fins comerciais, o autor enfatiza que as organizações humanas são meios de controlar um processo produtivo em qualquer esfera. Controlar uma organização humana significa detectar quais foram os fins, efeitos ou resultados não alcançados (que são os problemas da organização), analisas estes mais resultados buscando suas causas e atuar sobre estas causas de tal modo a melhorar os resultados [1,2].

Nesse contexto, deve-se reconhecer, antes de tudo, quais são os resultados que se deseja atingir para uma empresa [2], sabendo que o alvo principal de uma organização humana é satisfazer as necessidades das pessoas, então o objetivo, o fim, o resultado desejado de uma empresa é a Qualidade.

Seguindo essa linha de pensamento, a gestão da qualidade seria uma extraordinária ferramenta de "alavanca" que irá auxiliar no processo de competitividade a partir do momento que oferece ao mercado produtos livres de defeitos, entregas rápidas em associação com os programas operaci-onais que passam a contribuir plenamente para atender os requisitos dos clientes [2,3].

$\mathrm{Na}$ evolução histórica da indústria no início do século XX teve grande expansão, em especial, a invenção da produção em massa, como celebre exemplo de Henry Ford, que mudou a forma de se produzir, surgindo assim, um modelo de desenvolvimento extremamente importante na construção da estrutura da moderna administração $[1,2]$.

A busca por novos mercados, impulsiona as empresas no desenvolvimento da excelência tornando-as cada dia mais competitivas, e isso tem exercido um papel relevante para o aprimoramento das mesmas dentro de um contexto mundial $[2,3]$.

A competitividade está diretamente ligada à eficiência empresarial. Ela é a base do sucesso ou fracasso de um negócio onde há livre concorrência. Aqueles que conseguem manter um bom nível de competitividade prosperam e se destacam dos seus concorrentes, independente do seu potencial de lucro e crescimento $[3,4]$.

É importante lembrar que a competitividade é a correta adequação das atividades do negócio no seu microambiente [4].
A competição é um termômetro que serve para uso nas adaptações das atividades de uma empresa em relação ao seu nicho de mercado, balizando os caminhos a serem seguidos. Uma das estratégias utilizadas pelas empresas para serem competitivas é a diferenciação de seus produtos e de serviços $[3,4]$.

A empresa é entendida como um sistema que engloba recursos físicos, humanos e organizacionais, para transformar matérias primas em produtos, na forma de bens e serviços[2,3]. O maior desafio das empresas é sempre ofertar produtos e serviços que satisfaçam plenamente seus clientes, cobrindo seus custos e garantindo seus lucros.

Cerqueira Neto [3] define que: "as grandes em-presas se empenham na implementação de programas de qualidade total, cujos resultados não só garantem a plena satisfação dos clientes como também reduzem os custos de operação, minimizando as perdas, diminuindo consideravelmente os custos com serviços externos otimizando a utilização dos recursos existentes."

A empresa para ser competitiva precisa levar em consideração as ações de atuação dos seus concorrentes diretos, fornecedores, clientes, inovações (desenvolvimento de novos produtos, formas de trabalho, novos processos, etc), gerenciar materiais e operações e outros aspectos relevantes para garantir sua participação no mercado [4].

\subsection{Objetivo}

A finalidade deste artigo é abordar a adaptabilidade das organizações com relação a aspectos internos e externos para uma melhor utilização da Gestão da Qualidade e aumento da produtividade e consequente aprimoramento da sua própria competitividade dentro de uma ótica que permita a empresa sobreviver e vencer aos desafios proposto.

\subsection{Justificativa}

O tema se justifica pelo interesse em analisar o conhecimento, das empresas, sobre Sistemas de Gestão da qualidade, verificando como se iniciou a preocupação destas empresas em relação a qualidade de seus produtos pois durante a revolução industrial as empresas queriam vender o produto em grande escala sem preocupação com a qualidade do produto e a satisfação dos clientes.

\section{Análise da Competitividade com Sucesso}

\subsection{Qualidade e Produtividade}

Autores concordam que a qualidade deixou a ser pre- 
ocupação exclusiva dos técnicos, para ser de todos os envolvidos na organização. O conceito atual é que qualidade é adequação ao uso, cujos requisitos devem estar preestabelecidos. O mercado globalizado vem demandando novas abordagens em termos da questão da qualidade $[4,5]$.

Uma adequada gestão pela qualidade, que tem decisiva contribuição para alavancar à competiti-vidade, passou a ser decisiva para a sobrevivência das empresas. O fato é que o espaço para difi-cultar o acesso a mercados através do estabelecimento de tarifas acabou para a grande maioria dos países, passando estes a fazê-lo através das barreiras técnicas [5].

Um sistema com regras preestabelecidas deve ser oriunda de uma avaliação da conformidade e devidamente acompanhadas, que propicia adequado grau de confiança de que um produto, processo ou serviço atende aos requisitos de uma norma técnico. A preocupação constante, do empresário moderno, é de oferecer sempre produtos e serviços com altos índices de qualidade [7,6].

Qualidade e produtividade são fatores chave para a competitividade e sempre foi preocupação dos setores produtivos, em maior ou menor escala em diferentes setores $[7,8]$. O processo de gestão da qualidade obteve diferentes abordagens ao longo do tempo, sendo até hoje fator de sucesso para as empresas. Com o acirramento da competição a qualidade passou a ser uma questão de sobrevivência no mundo empresarial [8].

No Brasil, a partir do início da década de 90, vem sendo observado grande movimento em prol da melhoria da qualidade de produtos e serviços [8,9]. A criação de programas, tais como, o Programa Brasileiro da Qualidade e Produtividade, a abertura econômica que expôs as empresas brasileiras a um ambiente de grande competição, a evolução do cidadão brasileiro enquanto consumidor, que passou a exercer mais plenamente seus direitos e deveres e a estabilização da moeda foram fatores indutores e decisivos para esse movimento [9].

Os autores [10,11], concordam que ser competitivo é encontrar métodos para reduzir o esforço físico, encurtar o tempo de execução, diminuir custos, oferecer produtos e serviços com alta qualidade e bons preços de venda. Entretanto, é necessário que as empresas conheçam seus pontos fortes e fracos internos e externos.

Este conhecimento vem da análise de FOFA (Forças, Oportunidades, Fraquezas e Ameaças). Um parâmetro para saber se uma empresa tem competitividade, instaurase no confronto com outras empresas similares existentes em diferentes regiões [10].

A partir da evolução da qualidade para a moderna administração da qualidade total, houve um evolução na história da qualidade que tem três períodos, filosofias ou “eras" principais que serão abordadas mais à frente. A Gestão da Qualidade Total está sendo visualizada como uma forma de gerenciamento que, quando implementada e mantida, visa melhorar de modo contínuo o desempenho organizacional [10].

O processo de evolução da qualidade foram divididas em eras segundo Paladini [11] as quais descreveremos a seguir : Era da inspeção - Início do século XX: •Produtos são verificados um a um. • Cliente participa da inspeção. - Inspeção encontra defeitos, mas não produz qualidade. Era do controle estatístico - Década de 1930 : • Produtos são verificados por amostragem. - Departamento especializado faz controle da qualidade. • Ênfase na localização de defeitos. Era da qualidade total - Década de 1960: • Pro-cesso produtivo é controlado. Toda a empresa é responsável. • Ênfase na prevenção de defeitos. Qualidade assegurada.

\subsection{Evolução histórica da Qualidade}

A qualidade tem existido desde os tempos em que os chefes tribais, reis e faraós governavam. Os inspetores aceitavam ou rejeitavam os produtos baseados na observação de certos aspectos e características, se cumpriam ou não as especificações governamentais $[10,11]$.

O movimento da qualidade tem contribuído de forma marcante até os dias atuais na obtenção das vantagens competitivas junto às empresas. onde a evolução da qualidade pode ser analisada sob várias etapas [11]:

1a etapa (1900) - Controle da Qualidade pelo Operador: O controle da qualidade era efetuado por um trabalhador ou, um pequeno grupo era responsável pela fabricação do produto por inteiro, permitindo que cada um membro do grupo controlasse a qualidade de seu serviço.

2a etapa (1918) - Controle da Qualidade pelo Supervisor: Neste modelo, um supervisor assume a responsabilidade da qualidade referente ao trabalho da equipe, orientando as ações e executando as tarefas onde fosse necessário e conveniente caso a caso.

3a etapa (1937) - Controle da Qualidade por Inspeção: Nesta etapa, foca-se na finalidade de verificar se os materiais, peças, componentes, ferramentas e outros estão de acordo com os padrões estabelecidos. Deste modo seu objetivo é detectar os problemas nas organizações.

$4^{a}$ etapa (1960) - Controle Estatístico da Qualidade:

$\mathrm{Na}$ etapa do controle estatístico, surge nova forma de olhar à questão da qualidade através do reconhecimento da variabilidade na indústria.

5a etapa (1980) - Controle da Qualidade: Quando desta etapa, com enfoque em controle da qualidade, ela passou de um método restrito para um método mais amplo, que foi o gerenciamento. 
Esta oscilação na produção ocorre desde a variação da matéria-prima, de operários, de equipamentos, etc. A questão não era distinguir a oscilação, mas sim obter maneiras de separar as oscilações na produção que eram aceitáveis e as que indicassem problemas [11].

Deste modo surgiu o Controle Estatístico da Qualidade, no sentido de prevenir e resolver os problemas. Surgem também, neste período, as sete ferramentas básicas da qualidade na utilização da produção: Estratificação, Folha de Verificação, Diagrama de Pareto, Diagrama de Causa e Efeito, Histograma, Diagrama de Dispersão e Carta de Controle. Esta etapa se desenvolveu de forma lenta e permaneceu restrita às áreas de produção e em nível de chão de fábrica por muito tempo. Este modelo é aplicado nas empresas até os dias de hoje $[10,11]$.

\subsection{Ferramenta de qualidade (PDCA)}

Durante esta etapa, com o objetivo de se obter controles mais eficazes para o processo, surge também o ciclo do PDCA com americano Shewart, porém Deming foi o seu maior divulgador. $\mathrm{O}$ ciclo é dividido em 4 etapa básicas dentre as etapas existem 6 fases como mostra a Figura 1 [11].

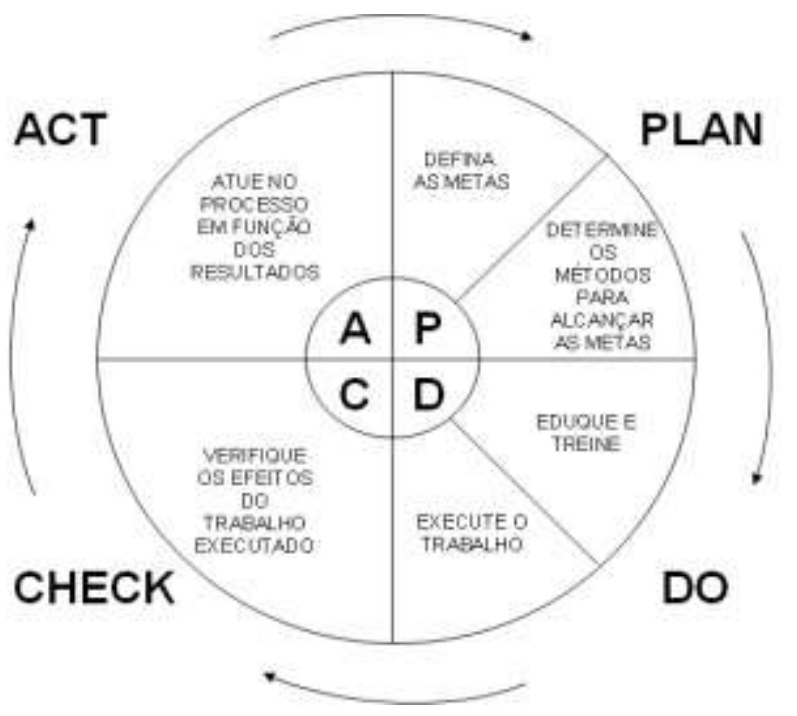

Figura 1: Fases do Ciclo PDCA [ Fonte: SILVA (2006)]

Primeira Fase $-\mathrm{P}($ Plan $=$ Planejamento $)$ Consiste em definir os objetivos, estratégias e metas. Definindo também os métodos a serem utilizados para atingir os objetivos .

Segunda Fase - D ( $D o=$ Executar $)$ Realizar o que foi planejado. Consiste em capacitar a organização de acordo com o que foi planejado e consequentemente implementar o que foi planejado.

Terceira Fase $-\mathrm{C}($ Check $=$ Verificar $)$ Verificar se os dados obtidos na execução em comparação com o que foi estabelecido para saber se os resultados estão sendo atingidos conforme estabelecidos.

Quarta Fase - A (Action = Agir) Realizar as correções necessárias com o objetivo de evitar a repetição de problemas.

A qualidade continuou com seu objetivo principal de prevenir e combater os problemas, apesar dos instrumentos se expandirem muito além da estatística. Estes instrumentos são: quantificação dos custos da qualidade, controle da qualidade, engenharia da confiabilidade e zero defeitos $[10,11]$.

Quando falamos de gestão da qualidade em fazer certo da primeira vez e prevenção das falhas logo podemos mencionar Crosby e o conceito de zero defeito. A qualidade deve ser definida em termos quantitativos para ajudar a organização a agir com base em metas tangíveis , onde a qualidade é medida pelo custo representada pela não conformidade $[11,12]$.

O sistema da qualidade proposto por Crosby está constituído pelo forte envolvimento da gerência e pessoal da empresa em torno do cumprimento das metas de qualidade [12].

O custo da qualidade é o elemento que mede o avanço conforme o planejado e as metas da empresa e identifica áreas problemáticas que requerem esforços concentrados. Com relação aos recursos humanos, Crosby enfatiza o uso de campanhas motivacionais, educação e treinamento, buscando o comprometimento do indivíduo com o zero defeito e redução de custos. O reconhecimento é efetuado através de prêmios [12].

\section{A era do Sistema de Gestão da Qualidade}

\subsection{Histórico}

Desde o surgimento das primeiras teorias de gestão de negócios, criados por Taylor, Fayol e Ford no início de 1900, já existia a preocupação não só com a produtividade, mas também com qualidade, embora o termo qualidade ainda não fosse o foco central da discussão. Ao estabelecer a divisão de tarefas, a especialização do operador, a padronização de componentes, estabeleceram-se os primeiros critérios de qualidade a serem apresentados por produtos e serviços, a isto chamou-se padronização $[11,12]$.

O Sistema de Gestão da Qualidade surgiu com a necessidade das empresas pensarem estrategicamente em o que produzir e como produzir. Quando se fala em produção estamos mencionando Henry Ford com a produção produzir automóveis em massa, com baixos custos e num pequeno intervalo de tempo [12]. 
A Ford inovou o mercado com seu sistema de gestão do trabalho: a linha de montagem. Ela permitiu um menor custo, tornando o automóvel mais acessível ao público. As produções em série eram respaldadas mediante normas estabelecidas, assim como acontece, hoje, com a ISO 9001.

A linha de montagem aplicada por Henry Ford, traz benefícios ao processo e, dentre algumas, podemos citar a eficiência da produção pois cada empregado era especialista em seu setor. Destaca-se, também, que o funcionário não precisa se deslocar de um setor a outro, pois esse possui as ferramentas necessárias no seu posto de trabalho [12].

A Ford Motor Company já foi a maior indústria automobilística do mundo, entre as décadas de 1950 e 1960. Porém, devido a falta de qualificação interna das produções de montagens, começou a perder mercado para um modelo mais enxuto (Lean Manufacturing), ou seja, com menos custos: Sistema Toyota de Produção [12].

A Toyota, no Japão, foi uma das primeiras empresas a utilizar o sistema de Gestão de Qualidade. O Sistema Toyota de Produção, prezava pela qualidade total imediata: excluir qualquer tipo de defeito, detectá-lo na origem e solucionar os problemas de origem. No toyotismo, procurava-se eliminar qualquer tipo de desperdício e aproveitamento do capital, funcionários e espaço de trabalho [12].

\subsection{A evolução da era do Sistema de Gestão da Qualidade}

A primeira era de gestão da qualidade, também chamada de era da inspeção, pode ser assim:

Foco $=$ O foco do sistema de gestão era o da verificação e acompanhamento in loco dos problemas de qualidade, o inspetor de qualidade era o responsável pela determinação da qualidade de um processo ou de um componente. Visão = A visão adotada pelos gestores da qualidade é a de que existem problemas, e os mesmos precisam ser resolvidos. Ênfase $=$ A preocupação em termos de qualidade, estava diretamente ligada a uniformidade dos produtos, como dizia Ford, "todos podem ter um carro Ford modelo T Preto". Método = O Método utilizado para medir e acompanhar a qualidade, estava baseado em instrumentos de medição, trenas, paquímetros e calibres, ditavam as regras de produtos considerados com ou sem qualidade. Responsável $=$ A responsabilidade por tudo que acontecia com a qualidade era do Departamento de Inspeção [12,13].

A segunda era dos sistemas de gestão qualidade, foi chamada de era do controle estatístico processo, onde o foco passou a ser a introdução de ferramentas estatísticas para o levantamento de informações a respeito do desempenho de produtos e processos, como segue: $\mathbf{F o c o}=\mathrm{O}$ foco da gestão da qualidade está no Controle de processos, produtos, componentes e operadores, que são controlados estatisticamente visando a manutenção e padrões de qualidade em tudo na organização. Visão= Embora novos procedimentos tenham sido incorporados ao dia-a-dia do processo produtivo, a visão do sistema ainda é o de que existem problemas e se existem precisam ser resolvidos. $\hat{\mathbf{E}} \mathbf{n} \mathbf{f a s e}=$ a principal mudança ocorrida nesta era diz respeito ao fato de que, percebeu-se a impossibilidade da realização da inspeção $100 \%$ no processo produtivo, o objetivo agora é a uniformidade de produtos com menos inspeções de processos. Método = as ferramentas e técnicas estatísticas estabelecem o nível de tolerâncias para as atividades, operações componentes. Responsável= a responsabilidade pelo desempenho da qualidade passa a ser dividida entre o departamento de fabricação e o departamento de engenharia.

A terceira era da gestão da qualidade, ficou conhecida como a era da garantia da qualidade. A mudança está na linha de pensamento de que a qualidade deve ser pensado como uma filosofia de gestão [13].

\subsection{Gestão da Qualidade X Certificação}

As certificações estão atreladas a Gestão da Qualidade, pois significa um modo de organização usado pelas empresas para garantir produtos e serviços com qualidade, que envolvem alta conformidade às especificações dos clientes $[13,14]$.

As variações das especificações podem mudar de acordo com a aparência do produto e ou através das respostas rápidas às mudanças de especificações impostas pelo mercado, pode mudar também face às baixas taxas de defeitos, tempo curto de manufatura e aspectos tecnológicos tais como: tecnologia básica de processo, tecnologia dos materiais, manuseio e tecnologia de produção [14].

O uso destas tecnologias associadas ao processo da Gestão da Qualidade possibilita aumento da produtividade e, por conseguinte, influencia a sua própria competitividade. Essas tecnologias podem representar um fator estratégico e competitivo para o ambiente operacional, com relação a grande variedade de opções de arranjos do fluxo de trabalho que repercutirá no pronto atendimento ao cliente [14].

O gerenciamento da qualidade total é uma abordagem voltada às operações gerenciais e portanto, a qualidade é inserida em um produto durante o processo operacional, e não acrescentada a ela na fase de inspeção. Com a atual realidade econômica, as empresas ao enfrentarem a competitividade, precisam constantemente avaliar suas estratégias de ação com relação à qualidade, e em muitos momentos deparam- se com a necessidade da certificação, ou seja, ISSO (International Organization for Standardization) [15]. 
O Brasil participa da ISO através da ABNT (Associação Brasileira de Normas Técnicas), que é uma sociedade privada, sem fins lucrativos, onde participam pessoas físicas e jurídicas, e reconhecida pelo governo brasileiro. A ISO 9001 foi desenvolvida para ser compatível com outras normas e especificações de sistemas de gestão, tais como a OHSAS 18001 de Saúde Ocupacional e de Segurança e a ISO 14001 de Meio Ambiente. Elas se integram perfeitamente através da Gestão Integrada [15].

A ISO 14001 é uma norma internacionalmente reconhecida que define o que deve ser feito para estabelecer um Sistema de Gestão Ambiental (SGA) efetivo. A norma é desenvolvida com objetivo de criar o equilíbrio entre a manutenção da rentabilidade e a redução do impacto ambiental; com o comprometimento de toda a organização. Com ela é possível que sejam atingidos ambos objetivos $[14,15,16]$.

A OHSAS 18001 Sistema de Gestão de Saúde e Segurança Ocupacional (SGSSO) promove um ambiente de trabalho seguro e saudável através de uma estrutura que permite à sua organização identificar e controlar consistentemente os riscos à saúde e segurança, reduzir o potencial de acidentes, auxiliar na conformidade legislativa e melhorar o desempenho geral $[15,16]$.

O processo de inspeção é o método tradicionalmente usado para manter o controle da qualidade. E o controle da qualidade moderno envolve o uso de técnicas estatísticas, planos de amostragem, variáveis e atributos, para detectar e tratar problemas relacionados à qualidade [16].

\subsection{Gestão da Qualidade x Sistema de Gestão Integrado}

As empresas que oferecem produtos e serviços com a melhor qualidade tem mais chance de vencer a concorrência e consequentemente tornar se mais competitivas. Porém hoje em atendimento às exigências de clientes e sobrevivência empresarial passou-se a incorporar, também, as questões relacionadas com o meio ambiente $\mathrm{e}$ saúde e segurança no trabalho, visando melhorar o alcance dos objetivos organizacionais $[16,17]$.

O sistema integrado de Gestão da Qualidade, Saúde e Segurança e Meio-Ambiente, uma vez implantado corretamente, minimiza e aperfeiçoa os processos e os componentes dos vários sistemas, criando um único sistema de gestão, centrando as atenções para um conjunto único de procedimentos, que associam as áreas de interesse com foco na melhoria contínua da gestão, buscando assegurar o atendimento dos requisitos legais e regulamentares aplicáveis às atividades das empresas [17].

\subsection{Administração da Produção X Manufa- tura}

A administração da produção e das operações tem passado por transformações imensas com as mudanças de mercado cada dia mais velozes, exigindo maiores esforços para o alcance de metas estratégicas e competitivas das organizações. As empresas precisam constantemente aprimorar sua produtividade, qualidade e eficiência [14, $18]$.

O processo parece simples, porém exige boa estruturação, comunicação fácil e ambiente de valorização do ser humano, e isso demonstra que nem sempre ser simples significa ser fácil. Para que estejam enquadradas neste contexto, algumas empresas adotaram e readequaram técnicas de qualidade, eliminação de linhas de produtos não competitivos, ᄀadoção de fluxo de produção mais eficiente, dentre outros processos que as tornem mais competitivas, trazendo a qualidade para dentro da empresa como um todo e não apenas ao chão de fábrica [18].

Percebe-se nitidamente a interação da qualidade com departamentos de P\&D (Pesquisa e desenvolvimento) e marketing. Tornou-se necessário sincronizar estratégias das empresas com o mercado e a manufatura, que atendam clientes, usuários e aqueles que os representam e influenciam, obtendo a consciência que a satisfação está relacionada com o que a concorrência oferece, porém, não sendo este o fator decisivo $[18,19]$.

A satisfação é conseguida durante toda a vida útil do produto não apenas na hora da compra, o que significa dizer que a produtividade está baseada em melhorias contínuas internas que refletiram externamente, desta forma, as empresas além de satisfazerem seus consumidores, devem também ser melhores que seus concorrentes.

A gestão da qualidade trata o processo de manufatura como um potencial alavancador de competitividade, e como parte destas estratégias, estão as obtenções de produtos com margem de erro zero, com entregas rápidas ao consumidor, cumprimento de prazos de entregas, colocação de novos produtos no mercado dentro do prazo preestabelecido, amplo "mix" de produtos conforme demanda do mercado, além de estratégias adequadas para produzir a baixos custos [18].

A gestão da qualidade auxilia o setor operacional a administrar redução de perdas e custos de operação, evitar estrangulamentos das linhas de produção, aprimorar métodos e testes de inspeção, otimizar tempo de produção, definir manutenções preventivas, eliminar retrabalhos e outras tomadas de decisão necessárias para concretizar a gestão [19].

Tanto as organizações de fabricação quanto as de serviços usam um processo operacional que converte insumos em produtos ou serviços. Esses tipos básicos de processos são oficinas de trabalho, produção contínua e produção por lote. A programação adequada e o controle 
do fluxo de trabalho são necessários tanto nas organizações de fabricação quanto de serviços $[18,19]$.

\subsection{Administração da Produção X Manufa- tura}

As empresas competitivas estão bem alinhadas em relação as suas informações. A informação é muito mais que dados processados, são dados coletados, organizados, ordenados, aos quais são atribuídos significados e contexto. Somente após esta interpretação os dados transformam-se em informações valiosas para tomada de decisões [13].

A informação está presente nas ações da empresa como um todo, no conhecimento do mercado, na definição de produtos, nas formas de atuação do processo operacional, interligando sistemas como suprimentos, compras, vendas e os demais envolvidos no cenário empresarial bem como os inter-relacionados. Tem por objetivo promover o conhecimento básico e orientar no que faz necessário em cada processo, função, desde que seja no momento certo e na quantidade adequada [14,19].

A informação significa dados em uso e seu valor é determinado pelo usuário. A informação utilizada no sistema empresarial pode ser organizada de acordo com o ciclo empresarial, agrupada pela sua similaridade e a estreita relação da organização em suas funções e processos com a cadeia de informação que garante tomada de decisão precisa em tempo real $[12,19]$.

Sobrevivência e sucesso empresarial dependem completamente da habilidade da organização em ajustar à dinâmica do ambiente empresarial. Mudanças em tecnologia geraram aberturas em acesso e controlam a informação e o conhecimento. $\mathrm{O}$ conhecimento é inerente à vantagem competitiva e a tecnologia converte desafios em oportunidades [12].

A administração do conhecimento é a solução para as capacidades técnicas da empresa, para criar o conhecimento que impulsionam a empresa adiante. Administração do conhecimento significa pensamento fora dos limites de práticas atuais, produtos, serviços e organizações $[12,19]$.

O ambiente organizacional moderno exige inovação, criatividade e ênfase no capital intelectual. A gestão do conhecimento é um processo, articulado e intencional, destinado a sustentar ou a promover o desempenho global da organização, com base no conhecimento $[13,14]$.

Ter controle, facilidade de acesso e manter um gerenciamento integrado sobre essas informações passou a ser um diferencial para que se possam atingir objetivos desejados, gerenciar informações não é mais o bastante para as empresas, que tem como principal objetivo é administrar conhecimento [13]. Conhecimento significa informa- ção interpretada, o que ela pode causar quando utilizada em determinadas tomadas de decisões. Saber como o meio reage às informações, antecipar às mudanças e ser bem sucedido nos objetivos a que se propõe [19].

A administração do conhecimento envolve pessoas, tecnologia processos, desta forma, utiliza o conhecimento acessível de fontes externas, embute e armazena conhecimento em processos de negócios, representa conhecimento em banco de dados e documentos, promove crescimento do conhecimento através da cultura das organizações e incentivos, transfere e compartilha conhecimento ao longo da organização e avalia o valor de ativos de conhecimento $[13,19]$.

$\mathrm{O}$ conhecimento é criado apenas pelos indivíduos e a eles este pertence. Uma organização não pode criar conhecimento sem as pessoas. O que pode fazer é apoiar pessoas criativas e prover contextos para que essas gerem conhecimento [10]. Além da geração e/ou aquisição de conhecimento, se faz necessário cuidar para que ele seja catalogado, transformado [19].

No contexto atual das empresas o conhecimento assume, cada vez mais, um papel central. Os recursos econômicos básicos passam a contar, além do capital, dos recursos naturais e da mão-de-obra com dados para a formação de conhecimentos necessários aos processos produtivos e de negócios [19].

O conhecimento tem o seu valor e para o ambiente organizacional o mesmo se faz presente através da aplicação de programas da qualidade, produtividade, capacidade de inovar, aplicando o conhecimento ao trabalho, criando os 'trabalhadores do conhecimento', abandonando de vez a antiga mão-de-obra e buscando ter consigo o 'cérebro-de-obra', fazendo com que novos desafios se façam presentes: a produtividade do trabalho com o conhecimento e a formação deste novo trabalhador possibilita a empresa competir e garantir sua permanência no mercado[13,14].

Para as organizações, conhecimento significa aplicar um conjunto de regras, procedimentos e relações a um conjunto de dados para que este atinja valor informacional. Uma informação idêntica, da mesma forma que um recurso físico, terá diferente valor para pessoas, locais e tempos diferentes, variando então seu valor econômico conforme o contexto [19].

Com relação a essa integração da gestão do conhecimento com os processos empresariais da organização, as tradicionais áreas ou departamentos funcionais da empresa continuam existindo, mas com novos desafios e propósitos[13,19]. 


\section{Conclusão}

As empresas estão sendo desafiadas a encontrar novas formas de organização e administração do processamento de produtos e serviços que atendam às exigências de qualidade. A qualidade está intrinsecamente relacionada à satisfação do cliente, portanto, a percepção do cliente é um fator-chave para avaliar as expectativas em relação a um produto ou serviço oferecido.

Porém nem sempre foi assim no mundo empresarial pois podemos lembrar do período da revolução industrial em que as empresas estavam preocupadas em produzir em massa sem se preocupar com a satisfação dos clientes. Atualmente o contexto empresarial bem diferente onde o mercado está cada vez mais competitivo e exigente fazendo com que as empresa estejam preocupadas com a necessidade e satisfação do cliente. Foi neste contexto que surgiu a necessidade da gestão qualidade dos produtos, evolução da tecnologia devido a necessidade de respostas rápidas e capacitação dos empregados para gerir todo esses sistemas.

\section{Referências}

[1] ALBRECH, K; LAWRENC, B. Serviços com qualidade e vantagens competitivas. São Paulo: Makron Books, 1997.

[2] BERGAMO, V. Gerência econômica de qualidade. São Paulo: Makron Books, 2000.

[3] CERQUEIRA, A. ;NETO, B.P. Gestão da qualidade princípios e métodos. São Paulo: Livraria Pioneira Editora, 1991.

[4] DEGEN, P. J. ; MELLO, A. A. A. O empreendedor: fundamentos da iniciativa empresarial. São Paulo: McGraw-Hill, 1989.

[5] HRAQDESKY. J. Aperfeiçoamento da qualidadee produtividade. São Paulo: Makron Books, 1997.

[6] KOTLER, K; ARMStronG, G. Princípios de Marketing. 9 ed. São Paulo: Prentice Hall, 2003.

[7] LANDAN, R. Tecnological, capital formalto and U.S. competitiveness: international productivity and competitiveness. New York: Oxford University Press, 1998.

[8] ALEXANDRE, L. LAS CASAS. Marketing de Serviços. 4 ed. São Paulo: Atlas, 2006.

[9] LONGENECKER, J.; MOORE, C.; PETTY, J.W. Administração de pequenas empresas. São Paulo: Makron Books, 1997
[10] MIRANDA, R. L. Qualidade total: rompendo as barreiras entre a teoria e a prática. 2 ed. São Paulo: Makron Books, 1994.

[11] PALADINI, E. P. Gestão da qualidade: teoria e casos. Rio de Janeiro: Elsevier, 2006.

[12] PRUSAK, L.; McGEE, J. V. Gerenciamento estratégico da informação. São Paulo: Campus, 1995. 244p.

[13] COLTRO, A. A gestão da qualidade total e suas influencias na competitividade empresarial. Disponível em: http:// www.ead.fea.usp.b. Acesso em Março de 2016.

[14] MARIN, P. L. Sistemas de gestão da qualidade e certificação iso 9001 na administração pública: uma análise crítica. Centro de Convenções Ulysses Guimarães. Braslia/DF. Junho de 2012. Disponível:

http://www.sgc.goias.gov.br/upload/arquivos/20 13-09/sistemas-de-gestao-da-qualidade.pdf. Acesso em Abril de 2016.

[15] ABNT NBR ISO 9000:2005. Sistemas de Gestão da Qualidade - Fundamentos e Vocabulário. Associação Brasileira de Normas Técnicas, 2005.

[16] ABNT NBR ISO 9001:2008. Sistemas de Gestão da Qualidade - Requisitos. Associação Brasileira de Normas Técnicas, 2008.

[17] DE CICCO, F. Sistemas Integrados De Gestão agregando valor aos sistemas ISSO 9000. Disponível: http://www.qsp.com.br. Acesso em Abril de 2016.

[18] PEINADO, J.; GRAEMI, A. R. Administração da produção (operações industriais e de serviço). 2004.

[19] FILHO, M. C. As ferramentas de qualidade no processo produtivo com enfoque no processo enxuto. Conselheiro Lafaiete, 2011. Disponível em: http://www.icap.com.br. Acesso em Abril de 2016. 